\section{From high performance to clinical practice}

\author{
Nadine Plotnikoff, ${ }^{1,2}$ Christopher Napier, ${ }^{3,4}$ Nadine Plotnikoff ${ }^{1,2}$
}

Hello to the world's BJSM community from your Canadian Sport Physiotherapy colleagues! At 1500 members strong, Sport Physiotherapy Canada (SPC) is the Canadian Physiotherapy Association's second largest special-interest group. With hard-working SPC provincial sections serving our members from British Columbia to the Maritimes, we are proud to measure ourselves as $5500 \mathrm{~km}$ from coast to coast. Just as we are learning from BJSM communities as far away from us as South Africa, and as close as the USA, we are confident we can add value from Canada-an international physiotherapy leader.

Many of you have crossed paths in the high performance world with SPC credential holders. For over 40 years, our credential programme has provided a training platform for Canadian physiotherapists interested in working in sport;

\footnotetext{
${ }^{1}$ Sport Physiotherapy Canada, Ottawa, Canada ${ }^{2}$ Form Physiotherapy, Vancouver, Canada

${ }^{3}$ Department of Physical Therapy, University of British Columbia, Vancouver, British Columbia, Canada

${ }^{4}$ Restore Physiotherapy, Vancouver, Canada
}

Correspondence to Nadine Plotnikoff, Form Physiotherapy, U16 - 601 West Broadway, Vancouver, BC V5Z 4C2 Canada; Nadine@formphysiotherapy.com
800 members have participated in some component of the SPC Certificate and Diploma processes. Each level of certification requires a written and practical examination and is achieved through extensive field and clinical preparation. Examiners, mentors and Sports First Responder instructors form the robust member group surrounding this programme.

We have a long-standing role in providing the selection for members of Canadian Major Games medical teams. Recent acknowledgements of our credential holders' skill sets include acceptance into the approved educational pathways of the International Federation of Sports Physiotherapy. You will also see our credential holders working at the highest levels in the NHL, NBA and Major League Soccer professional leagues.

Providing quality educational experiences is important to us. We have just finished hosting our second annual concussion symposium. We remain committed to offering a multi-disciplinary concussion learning event every year and we are proud of our physiotherapy concussion leaders who have an important presence in international circles around this topic. Our famous 'Grey Cup' weekend (Canadian
Football League) has provided the time and place for our Concussion symposium, allowing our attendees to experience a piece of Canadiana. Are we unique in our love of a frozen football field on a bitter cold November day? I think we must be.

So now, in addition to regional events, we look forward to offering November 2018's Concussion Symposium in Edmonton, Alberta and October 2019's World Congress of Sport Physiotherapy, to be held in Vancouver, BC. Please join us at these events. We would enjoy renewing or making your acquaintance there.

In the meantime, we offer you this year's SPC edition of the BJSM. In it, we offer you a mix of articles designed to create some excitement around the topic of 'High Performance to Clinical Practice', a theme which we intend to broaden at our October 2019 IFSPT World Congress in Vancouver.

\section{Competing interests None declared.}

Provenance and peer review Commissioned; internally peer reviewed.

(C) Article author(s) (or their employer(s) unless otherwise stated in the text of the article) 2017. All rights reserved. No commercial use is permitted unless otherwise expressly granted.

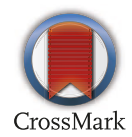

To cite Plotnikoff N, Napier C, Plotnikoff N. Br J Sports Med 2017;51:1641.

Br J Sports Med 2017;51:1641. doi:10.1136/bjsports-2017-098606 